Centro Universitário de Brasília - UniCEUB

Faculdade de Ciências da Educação e da Saúde - FACES

Programa de Iniciação Científica

LUCAS PARCA GUARITÁ

A LITERATURA COMO POSSIBILIDADE DE COMPREENSÃO DE PROCESSOS SUBJETIVOS: UMA ANÁLISE DO LIVRO O CONTO DA AIA.

Brasília 
Centro Universitário de Brasília - UniCEUB

Faculdade de Ciências da Educação e da Saúde - FACES

Programa de Iniciação Científica

\section{LUCAS PARCA GUARITÁ}

\section{A LITERATURA COMO POSSIBILIDADE DE COMPREENSÃO DE PROCESSOS SUBJETIVOS: UMA ANÁLISE DO LIVRO O CONTO DA AIA.}

Relatório final de pesquisa de iniciação Científica apresentado à Assessoria de Pós-Graduação e Pesquisa.

Orientação: Professora Dra. Valéria Deusdará Mori. 


\section{Dedicatória}

O presente trabalho é dedicado ao professor Fernando González Rey, pessoa da qual tive a honra e o privilégio de conhecer. Minha caminhada na teoria da subjetividade fica na minha história e contribuiu para meu crescimento e na forma como enxergo o mundo. O professor leu muito, escreveu, amou e foi amado, era um cientista, um ser pensante neste belo planeta, comunicou-se com o mundo de forma brilhante, sua história está espalhada e só está no começo.

A imagem de um ser humano forte, com uma energia única ficará em nossas mentes por muito tempo, que seu afeto se espalhe cada vez mais, esse cubano deixa sua marca na história da psicologia. Lembro-me dele sempre repetir "Gosto de jovens pensantes!" espero eu, conseguir ser um jovem pensante e contribuir com um terço que esse grande mestre contribuiu para a ciência e para a produção de novas subjetividades. 


\section{Agradecimentos}

Gostaria de agradecer primeiramente ao UniCEUB, apoiar a pesquisa é fundamental, principalmente em momentos de crise como os que passamos atualmente na educação. Agradeço à minha orientadora Valéria Mori por todos os ensinamentos e apoio ao longo desta pesquisa, te tenho com amiga e inspiração de vida, não tenho palavras para expressar todo meu respeito e admiração. Agradeço ao professor Fernando González Rey por toda sua sabedoria, sua teoria deixa marcas em minha trajetória acadêmica. Por fim, mas não menos importante, agradeço imensamente a minha companheira de vida Vanessa Santos, que leu e releu este trabalho inúmeras vezes com carinho, crítica e paciência, esse trabalho não estaria pronto se não fosse pelo seu apoio. 
"Eu estava adormecida.

Foi assim que deixamos acontecer.

Quando massacraram o Congresso nós não acordamos.

Quando culparam os terroristas e suspenderam a constituição nós também não acordamos."

- The Handmaid's Tale 


\section{A LITERATURA COMO POSSIBILIDADE DE COMPREENSÃO DE PROCESSOS SUBJETIVOS: UMA ANÁLISE DO LIVRO O CONTO DA AIA.}

\section{Lucas Parca Guaritá - UniCEUB}

lucasparca@gmail.com

Valéria Deusdará Mori - UniCEUB, professora orientadora

morivaleria@gmail.com

\section{RESUMO}

O presente trabalho trata de uma análise construtivo-interpretativa proposta por González Rey $(2011,2015,2017)$ do livro "O Conto da Aia" da autora Margaret Atwood escrito originalmente em 1985, que traz uma distopia futurista, na qual se é exposto diversas questões sobre as condições femininas, de uma sociedade religiosa, patriarcal, machista, e conservadora. Tal análise teve por objetivo compreender diferentes processos subjetivos que se expressam em uma obra literária. Busco entender portanto a arte como expressão do mundo em que vivemos, e a forma como a subjetivamos perpassa a cultura e a sociedade, bem como a história de vida de cada indivíduo. Tendo como base o livro "O Conto da Aia" pode-se discutir diferentes questões, tais como: machismo, relações de poder, meio ambiente e violência. Buscou-se entender como essas questões são subjetivadas pela indivíduo-sociedade.

Palavras-chave: Subjetividade. Contemporaneidade. Literatura. 


\section{SUMÁRIO}

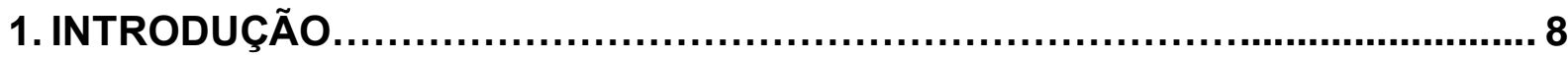

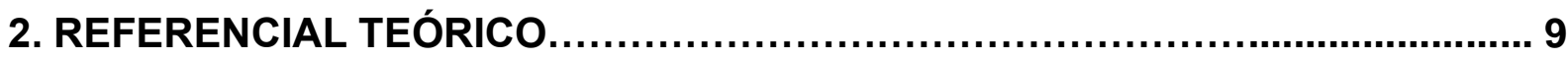

3. METODOLOGIA

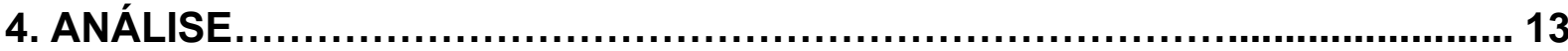

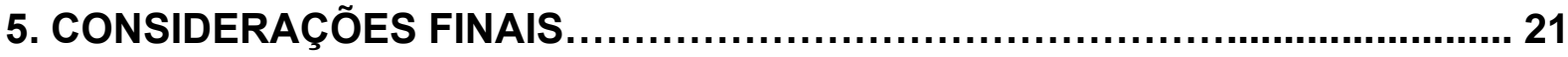

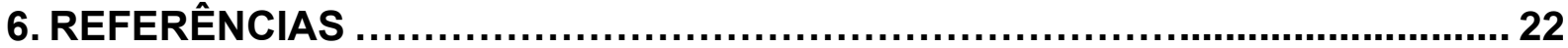




\section{Introdução}

O uso da arte como possibilidade de reflexão dos diferentes processos subjetivos tem se tornando cada vez mais comum na contemporaneidade, autores como Dunker (2003); Heck (2014) e Zizek (2018) são exemplos de pesquisadores que vem aprofundando seus estudos nesta área. Segundo Homem (2012) a arte representa uma expressão do mundo em que vivemos, e a forma como a subjetivamos perpassa a cultura e a sociedade, bem como a história de vida de cada indivíduo.

Por acreditar, assim como Leite (2003), que a análise de uma obra literária, tal como as demais artes, é um recurso para a ciência psicológica, o presente trabalho consiste em uma análise de uma obra literária, em que se buscou traçar paralelos com os acontecimentos da contemporaneidade. Para isso, se fez uma análise construtivainterpretativa, proposta por González Rey e Martínez (2017)

Sendo assim, o presente trabalho teve por objetivo mostrar que o uso da literatura como reflexão da contemporaneidade é algo não apenas possível, como também uma excelente fonte de discussões, sendo um importante recurso para as ciências psicológicas. O objetivo aqui não é o de psicologizar a arte e sim, aprender com ela, possibilitando avançar na compreensão dos diferentes processos subjetivos da contemporaneidade.

A obra escolhida para o presente trabalho foi, "O Conto da Aia" de Margaret Atwood, escrito originalmente em 1985, que retrata uma distopia futurista, na qual são expostas diversas questões sobre as condições femininas, de uma sociedade religiosa, patriarcal, machista, e conservadora. Em 2017, a obra de Atwood foi transformada em uma série televisiva nos EUA, o que ajudou na repercussão de seu livro, estando desde então em diversas listas de mais lidos, como a do The New York Times e a da Amazon. A obra apesar de distópica, retrata diversos acontecimentos que podem ser observados na sociedade contemporânea. 


\section{Referencial teórico}

A arte nos possibilita refletir sobre diferentes processos da vida, seja um filme, um livro, uma fotografia ou um grafite no muro, todos têm algo a transmitir. Alguns nos levam a nossa infância, outros nos fazem pensar no presente. Segundo Homem (2012), o campo da arte, perpassa o campo da imitação. Para que esta ocorra, é necessário algo a ser imitado e alguém que se interesse. O "objeto" a ser recriado é qualquer um, real ou imaginário. Portanto, a arte representa uma expressão do mundo em que vivemos, e a forma como a subjetivamos perpassa a cultura e a sociedade, bem como a história de vida de cada indivíduo. $\mathrm{Na}$ arte, tal como na história e na filosofia, deve-se buscar encontrar uma interpretação mais adequada ou eficaz para os problemas que cada época enfrenta, ainda que estes não tenham sido os da sua época ou da do artista. (LEITE, 2003)

Dentro da psicologia, o uso da arte como possibilidade de reflexão, ainda é pouco usada, sendo limitada a certas abordagens e a autores específicos, tais como os trabalho de Leite (2003), Rodrigues (2013), Heck (2014) e Dunker (2017). Em outras ciências como comunicação social e história, é mais comum trabalhos que relacionem o mundo contemporâneo com o mundo das artes. Partindo do ponto que a arte e a vida fazem paralelo uma com a outra, acredito ser importante que a psicologia avance em seus estudos.

Segundo Harari (2018), as fronteiras entre a realidade e a ficção têm se mostrado cada vez mais tênues, em alguns momentos parece que estamos vivendo uma história já contada e é nesse ponto que o autor questiona se haverá ainda uma fronteira nítida entre realidade e ficção. Para Lacan (1988), a arte como saber, sempre antecipa a psicanálise, logo trata-se de não psicologizar a arte e sim, aprender com ela, pois a arte pode nos ajudar a avançar.

Sendo assim, o presente trabalho consiste em uma análise de uma obra literária, onde buscou-se traçar paralelos com os acontecimentos da contemporaneidade, por acreditar assim como Leite (2003), que uma análise literária, tal como as demais artes, é um recurso para a ciência psicológica. Segundo esse mesmo autor, a literatura, assim como todo pensamento produtivo, é uma forma de interação do indivíduo com o social e a cultura, onde a mesma "só adquire sentido na medida que é recriada pelo leitor" (LEITE, 2013, p. 215) por isso pode ser usado como recurso para a compreensão de processos subjetivos. 
A análise feita no presente trabalho foi uma análise construtiva-interpretativa, que define a ação de pesquisa segundo González Rey e Martínez (2017) como simultaneamente teórica e dialógica. O diálogo na presente pesquisa se deu entre o pesquisador e a obra literária, onde se fez uma interpretação do texto em paralelo aos acontecimentos da contemporaneidade.

"O modelo teórico, no curso da pesquisa, está sempre envolvido com as
decisões e os posicionamentos do pesquisador que se torna um interlocutor
das novas ideias e hipóteses que ele vai gerando, as quais levam a
aprofundar as hipóteses que caracterizam esse modelo no momento atual ou
a modificá-lo, apoiando-se em novas construções que se articulem melhor
com as novas hipóteses emergentes." (GONZÁLEZ REY e MARTINÉZ, 2017,
p. 89)

Tendo como base a citação acima, podemos entender que a partir do diálogo existente entre pesquisador-literatura, passa-se a desenvolver o problema a ser investigado, que vai se aprofundando, esclarecendo e desdobrando ao longo do curso da pesquisa. Logo as questões aqui trazidas e analisadas não vieram a priori, mas sim ao longo da leitura, dentro desse cenário a informação que vai sendo relevante para o problema estudado não aparece diretamente no texto, nem no que ali está descrito, mas sim nas hipóteses que vão ganhando força, a partir de indicadores que o pesquisador constrói a partir de suas interpretações.

Segundo González Rey e Martínez (2017), as hipóteses neste tipo de pesquisa não representam construções a priori para serem comprovadas, mas sim nos caminhos nos quais o modelo teórico vai ganhando capacidade explicativa. Isso, em uma obra literária implica não trazer hipóteses antes de sua leitura, mas sim a partir dela, traçando paralelos com a própria experiência do pesquisador, que não é neste caso isento do processos da pesquisa.

Portanto, não se busca categorizar de forma descritiva e distante a narrativa, mas sim analisar o que se está sendo representado, levando em consideração os mais diferentes processos, avançando para além das representações centradas na narrativa apresentada, buscando assumir os processos subjetivos ali apresentados, como complexos, onde há uma articulação do social e do individual, avançando para além do que está explicitado. Sendo assim, demanda uma leitura de processos simbólicos e emocionais que se expressam na obra literária, emocionais por entender que a forma como cada leitor percebe uma obra é singular.

Nesse sentido, enquanto pesquisador, há a leitura do texto de forma crítica, mas também há mobilização de diferentes processos subjetivos, pois como traz 
González Rey e Martínez (2017), o pesquisador é, assim como seu "objeto" de estudo, mobilizado por esses processos.

Esta proposta teórica tem avançado em diferentes debates, o que nos possibilita discutir diferentes aspectos da vida humana. No entanto, há de se reconhecer que pouco se discutiu sobre a articulação entre literatura e Subjetividade, o que motivou a escrita do presente trabalho.

A obra aqui escolhida para ser analisada foi, "O Conto da Aia" de Margaret Atwood, escrito originalmente em 1985, que traz uma distopia futurista, na qual se é exposto diversas questões sobre as condições femininas, de uma sociedade religiosa, patriarcal, machista, e conservadora. Segundo Parucker (2018), a história retrata a tentativa de uma mulher de se fazer existir, buscando sobreviver neste mundo e na história vivida.

Em 2017, a obra de Atwood foi transformada em uma série televisiva nos EUA, o que ajudou na repercussão de seu livro. Sua obra levanta toda uma série de questões que se encontram nas bases do feminismo: tais como, as relações existentes entre as mulheres, o papel de reprodução e alimentação, a sexualidade, a repressão, a violência contra mulheres, a relação entre o masculino e o feminino e resistência ao sistema.

A história narrada não está tão distante da realidade vivida, alguns dos pontos ali tratados fazem paralelo com acontecimentos recentes e da história da humanidade, como por exemplo o caso abordado pela Folha de S.Paulo (2019) que traz o relato de vítimas da brutal ditadura do Khmer Vermelho no Camboja, que obrigou mais de 200 mil desconhecidos a se casarem para aumentar a natalidade do país entre 1975 à 1979 além do assassinato de mais de um milhão de pessoas.

Segundo uma matéria do Nexo (2017), a autora de "O conto da Aia" traz que sua regra é não colocar em um livro nada que já não houvesse acontecido, sem leis imaginárias, dispositivos imaginários ou atrocidades imaginárias, fatos como o uso de roupas específicas, questões relacionadas à fertilidade, controle de mulheres e bebês, a proibição da leitura e disputa entre grupos, foram todos inspirados em acontecimentos reais da humanidade.

Partindo da ideia de que a história narrada faz paralelos com a realidade, busquei fazer uma análise construtiva interpretativa do livro, trazendo questões 
relacionadas a contemporaneidade do Brasil e do mundo, utilizando como aporte teórico a teoria da subjetividade e o método construtivo-interpretativo.

\title{
3. Metodologia
}

A metodologia construtivo-interpretativo parte da ideia de que o objeto do conhecimento científico é conhecido a partir de sua construção teórica, pelas consequências deduzidas daquela construção. Segundo González Rey e Martínez (2017) essa proposta identifica a pesquisa como uma criação.

\begin{abstract}
"Qualquer aspecto da informação produzida no momento metodológico pode se transformar num indicador dentro de momentos diferentes do processo de investigação, assim como um indicador pode simultaneamente representar sentidos diversos e se incorporar por duas ou mais vias no processo de construção da informação." (GONZÁLEZ REY, 1997, p. 114, apud GONZÁLEZ REY e MARTINEZ, 2017, p .30).
\end{abstract}

Os sentidos subjetivos e as configurações subjetivas precisam ser construídos no decorrer da pesquisa e são legitimados por indicadores, informações que não aparecem de forma direta, mas que são essenciais para serem "novas inteligibilidades teóricas sobre o problemas estudado" (González Rey e Martínez, p. 39, 2017).

Antes de continuarmos, se faz necessário a compreensão de dois importantes conceitos dentro desta perspectiva teórica. O primeiro é o conceito de sentidos subjetivos, que são unidades simbólico-emocionais, que podem ser traduzidos como qualquer experiência significativa para a pessoa que a produz. Vale destacar que esses sentidos subjetivos perpassam a subjetividade social e são produções individuais ou grupais. As configurações subjetivas sintetizam tanto a pluralidade dessas experiências de história de vida, como os múltiplos contextos sociais, que atualizam a experiência presente de uma pessoa ou grupo social, isto é, as configurações subjetivas são processos mais significativos, organizados e estáveis, o que possibilita novas produções e configurações subjetivas (GONZÁLEZ REY \& MARTINEZ, 2017).

Os processos de sentido subjetivo numa configuração subjetiva só ganham inteligibilidade em uma pesquisa a partir das construções do pesquisador, que irá se alimentar de significados que são produzidos gradualmente. Essa lógica configuracional (GONZÁLEZ REY, 2002, apud GONZÁLEZ REY \& MARTINEZ, 2017), exclui o determinismo e abre caminho aos processos explicativos a qualidade individual. 
Sendo assim, "os conceitos da teoria tornam-se também recursos de valor epistemológico e ferramentas metodológicas" (GONZÁLEZ REY \& MARTINEZ, p. 46, 2017). Os trechos de informação aqui trazidos foram possíveis a partir da leitura do livro "O Conto da Aia", que traz a história de Offred, uma Aia que perde seu marido e filha e que pertence a classe de mulheres mantidas para fins reprodutivos. Os diferentes processos subjetivos ali apresentados, foram importantes vias de produção de informação, sendo possível trazer diferentes indicadores relacionados à contemporaneidade.

\section{Análise}

Dentro da proposta elaborada por González Rey (2017), a subjetividade social é caracterizada como sendo um sistema integral de configurações subjetivas, sociais e individuais. Quando se fala em subjetividade social dentro desta abordagem, não se define como uma entidade portadora de características universais e estáticas, ela não está dada por elementos gerais que caracterizam o funcionamento aparente da sociedade, mas sim pelas configurações subjetivas sociais e individuais que a integram e pela maneira pela qual discursos, valores e outras produções sociais emergem nessa configuração, ela é produzida na relação com a cultura e dos acontecimentos que ali estão ocorrendo. Logo, não existe uma realidade dada e sim produzida.

A subjetividade social em "O conto da Aia" é construída em Giliade onde antes se encontrava os Estados Unidos da América. Um movimento fundamentalista de reconstrução cristã autointitulado "Filhos de Jacó" realizam um golpe e suspendem a Constituição dos Estados Unidos sob o pretexto de "restaurar a ordem". Esta ditadura teocrática busca reorganizar a sociedade depois de um caos provocado por desastres naturais e infertilidade em massa de mulheres e plantas.

Nas sociedades contemporâneas, segundo Crary (2016) é inseparável a lógica $24 / 71$, as catástrofes ambientais, em que se exige de forma permanente o desperdício sem fim, e na interrupção fatal dos ciclos e estações das quais depende a integridade ecológica do planeta. No Brasil, o governo atual parece não estar dando a devida 
atenção à integridade ecológica, o governo de Bolsonaro contingenciou 96\% do valor que seria usado no ano de 2019 na Política Nacional sobre Mudança do Clima2 (ÉPOCA, 2019) que buscava atender a compromissos assumidos pelo Ministério do Meio Ambiente, as intervenções contra o aquecimento global estão entre as mais afetadas pelo bloqueio de recursos feito pelo governo federal. Os repasses ao Instituto Brasileiro do Meio Ambiente e dos Recursos Naturais Renováveis (Ibama), também sofreram um corte de $24 \%$, tudo isso na mesma semana em que a WWF divulgou um estudo revelando que o planeta perdeu metade de seus animais nos últimos 40 anos (MAMILOS, 2019).

Segundo Gross (2018), a terra fadigou, o século XXI será o do esgotamento, a humanidade coloca à natureza no seu limite, fecundidade das terras extenuada, recursos exauridos e estoques esgotados. Em o Conto da Aia, sinais deste caos vinham sendo sinalizados durante anos e ignorados pela população, no trecho abaixo retirado do livro, podemos observar como as pessoas não se atentaram aos acontecimentos que ali vinham sendo produzidos.

"Foi depois da catástrofe, quando mataram a tiros o presidente e metralharam o Congresso, e o exército declarou um estado de emergência. Na época atribuíram a culpa aos fanáticos islâmicos.

Mantenha a calma, diziam na televisão. Tudo está sobre controle.

Fiquei atordoada. Todo mundo ficou, sei disso. Era difícil de acreditar. O governo inteiro massacrado daquela maneira. Como conseguiram entrar, como isso aconteceu?

Foi então que suspenderam a constituição. Disseram que seria temporário. Não houve sequer nenhum tumulto nas ruas. As pessoas ficavam em casa a noite, assistindo a televisão, em busca de alguma direção" (ATWOOD, p. 208, 2017).

Harari (2018) traz que a crise ecológica iminente, a ameaça diária das armas de destruição em massa e o surgimento de novas tecnologias disruptivas não podem ser ignoradas, mas que em um planeta com 7 bilhões de pessoas, existem 7 bilhões de agendas, e que todos tem problemas muito mais "urgentes" do que o aquecimento global ou a crise da democracia. No livro de Margaret Atwood, a personagem principal traz exatamente essas diferentes agendas, como as pessoas não se atentaram ao que vinha ocorrendo e quando ocorreu, era tarde para impedir.

"Houve passeatas, é claro, muitas mulher e alguns homens. Mas foram menores do que se teria imaginado. Creio que as pessoas estavam com medo. E quando se tornou público

2 A Política Nacional sobre Mudança do Clima (PNMC) oficializa o compromisso voluntário do Brasil junto à Convenção-Quadro das Nações Unidas sobre Mudança do Clima de redução de emissões de gases de efeito estufa. 
que a polícia ou o exército, ou fossem lá quem fossem, abririam fogo quase que tão logo quaisquer passeatas começassem, as passeatas pararam." (ATWOOD, p. 215, 2017)

Durante o conto, Offred (personagem principal e narradora da história) traz diversos momentos em que se buscaram alternativas de luta contra essa nova realidade, depois que se percebeu que as passeatas não iriam funcionar, o poder de força da população revoltosa muito inferior, passou-se a tentativas de fuga, mudar de país, porém o controle intenso e a força bruta das autoridade fizeram com que as pessoas ficassem anestesiadas, com medo de continuar tentando, se conformando com a realidade, na espera de alguma nova informação.

Segundo Hobbes (2003), de todas as paixões, o medo é a que menos faz os homens tenderem a violar as leis. Arendt (2012) traz que o terror como substituto da propaganda, em que se mata pequenos grupos revoltosos, mostra a população o perigo que pode acarretar o simples fato de pertencer a um grupo que não o hegemônico, esse tipo de terror dirigido contra às populações é valioso, serve como uma "propaganda de força", mostrando que suas forças são maiores que qualquer autoridade e que é melhor pertencer a eles do que ir contra eles. Em regimes totalitários, o verdadeiro drama é que o terror é aplicado contra uma população já completamente subjugada.

Nas sociedades contemporâneas, o medo é constantemente usado para controlar a população, a diferença é que as formas como são implantadas aparentam não existirem e muitas vezes somos nós mesmos os responsáveis por esse controle, "não saia de casa", "não faça barulho", "a cidade está perigosa", "volta cedo pra casa", "polícia mata inocente", "não veste essa roupa", etc. O medo, no contemporâneo, passa a ser naturalizado no dia a dia das pessoas.

Frases como as aqui trazidas são comuns e constantemente replicada por nós, segundo Han (2017), na contemporaneidade, o imperativo do obedecer recai sobre si mesmo e a pressão do desempenho, onde o explorador é ao mesmo tempo o explorado. Agressor e vítima não podem mais ser distinguidos. O efeito deste processo é a negação da subjetividade do outro, onde enxerga-se apenas os resultados, rejeitando a dimensão complexa da relação Estado cidadão (ROCHA, 2017). Seguimos com mais alguns trechos de informação:

"Nós paramos, juntas como se atendendo a um sinal e olhamos para os corpos. Não faz mal se olharmo. Espera-se que olhemos: é para isso que estão lá, pendurados no Muro. Às vezes ficam lá expostos por dias a fio, até chegar um novo lote, de modo que o maior 
número possível de pessoas tenham a oportunidade de vê-los." (O Conto da Aia, p. 44, 2017)

"Na semana passada mataram a tiros uma mulher, bem aqui. Era uma Martha Estava remexendo em sua túnica em busca do passe, e pensaram que estivesse apanhando uma bomba." (ATWOOD, p. 31, 2017)

Ao longo da narrativa, momento de violência e repressão são constantes, se uma mulher é pega lendo, seduzindo um homem, roubando ou sob suspeita de rebelião é presa, torturada, mandada para campos de concentração ou morta. Quando pensamos no contemporâneo, este último trecho nos traz a memória o "acidente" que ocorreu no Rio de Janeiro esse ano, o assassinato do músico Evaldo Rosa, alvejado por nove militares que dispararam 80 tiros no carro em que ele e sua família se encontravam (FOLHA DE S.PAULO, 2019). Isso nos mostra que as configurações da subjetividade vão sendo alimentada pelos discursos de raça, classe social, gênero, e como a reação das pessoas nos mostram um indicador da naturalização do medo, do terror e da autoridade. Foram oitenta tiros, e os militares responsáveis por tal barbárie já se encontram em liberdade, fica a pergunta, se Evaldo fosse branco e rico, esses militares estariam soltos?

É interessante pensarmos como o medo e o terror vão sendo produzidos e subjetivados pelas sociedades, o quanto esses processos podem ser paralisantes e ao mesmo tempo serem produtores de novas configurações subjetivas, em que se busca romper com a lógica dominante, levando as pessoas a lutarem por seus direitos, assim como ocorreu/ocorrem em movimentos negros, feministas, LGBTQI+.

Em o conto da Aia, diversos grupos perdem seus direitos, nesta nova e rígida ordem social, mulheres não podem ler, trabalhar ou possuir nada, todas as mulheres são divididas em castas, as tias que estão no topo da cadeia feminina, são responsáveis por formar as Aias e por essa função de honra tem alguns privilégios como poder circular pela cidade, ler e portar armas brancas. As esposas dos comandantes cujo papel é cuidar do lar e apoiar emocionalmente seus maridos, as empregadas domésticas que cuidam das casas dos comandantes e as Aias que devem apenas gerar os filhos dos comandantes. "Somos úteros de duas pernas, apenas isso: receptáculos sagrados, cálices ambulantes." (ATWOOD, p. 165, 2017)

Aqui podemos pensar em como essa subjetividade social expressa 0 patriarcado, em que as mulheres perdem inúmeros direitos. $O$ uso do patriarcado enquanto um sistema de dominação dos homens sobre as mulheres permite segundo Morgante e Nader (2014) visualizar que a dominação não está presente somente na 
esfera familiar, tampouco apenas no âmbito trabalhista, ou na mídia ou na política. O patriarcalismo, segundo as autoras, compõe a dinâmica social como um todo, estando inclusive, inculcado no inconsciente de homens e mulheres individualmente e no coletivo enquanto categorias sociais.

Vale ressaltarmos que não é possível pensar o patriarcalismo, sem pensar no machismo, sendo as sociedades patriarcais eminentemente machistas. Essa lógica é levada ao seu máximo no conto de Atwood, mas não está longe da realidade contemporânea, basta olhar as taxas de feminicídio que crescem a cada ano, no Brasil esse crescimento foi de 34\% entre os anos de 2016 e 2018 segundo o Conselho Nacional de Justiça (CORREIO BRAZILIENSE, 2019). O fato das mulheres trabalharem, em média, três horas por semana a mais do que os homens, combinando trabalhos remunerados, afazeres domésticos e cuidados de pessoas e ainda ganharem em média, $76,5 \%$ do rendimento dos homens (IBGE, 2018) revela essa falta de direitos iguais entre homens e mulheres.

A personagem principal do conto, Offred traz essa reflexão ao longo do livro, destaco aqui um trecho do qual exemplifica bem tal situação, que ocorria antes da mudança de poder.

"As mulheres não eram protegidas naquela época. Lembro-me das regras, regras que nunca eram explicadas em detalhes, mas que toda mulher conhecia: não abra sua porta para um desconhecido, mesmo se ele disser que é da polícia... Não pare na estrada para ajudar um motorista fingindo estar em dificuldades. Mantenha as portas trancadas e siga em frente. Se alguém assobiar, não se vire para olhar. Não entre numa lavanderia máquinas de autoatendimento sozinha, à noite." (ATWOOD, p 35, 2017)

Em O Conto da Aia, os homens que estão fora da elite, também perdem alguns de seus direitos, ou pertencem a um grupo de polícia de elite e espionagem chamada "Olhos" ou são servos que não se quer "tem o direito a uma mulher".

A elite subordina as pessoas a lógica dominante, onde as mesmas não devem ter um posicionamento próprio, a sociedade em O Conto da Aia, assim como nas sociedades contemporâneas, pretende gerar corpos submissos e produtivos, dispostos a trabalhar nos diferentes espaços, enquanto suas potências políticas são sufocadas a fim de inibir as tentativas de rebelião (SIBILIA, 2015).

Na sociedade de Atwood, qualquer suspeita de subversão, qualquer mínimo desvio dos costumes e regras é o suficiente para ser sequestrado pelos olhos, 
torturado, morto ou enviado para um campo de trabalho forçados para manusear lixo tóxico, não importando a que casta pertença.

"Viramo-nos e caminhamos juntas passando pelas grandes casas, em direção à parte central da cidade. Não temos permissão para ir lá exceto em pares. Supostamente isso é para nossa proteção, embora a ideia seja absurda: já somos bem protegidas. A verdade é que ela é minha espiã, como eu sou a dela. Se alguma de nós duas escapulir da rede por causa de alguma coisa que aconteça em uma de nossas caminhadas diárias, a outra será responsável.

Esta mulher tem sido minha parceira há duas semanas. Não sei o que aconteceu com a outra, a anterior. Um belo dia, ela simplesmente não estava mais lá, e esta aqui estava em seu lugar. Não é o tipo de coisa a qual você faça perguntas, porque as respostas não são, geralmente, respostas que você queira conhecer. De qualquer maneira não haveria uma resposta." (ATWOOD, p 29, 2017)

Aqui, podemos pensar no conceito de Panóptico, que segundo Foucault (1987), consiste em um espaço fechado e vigiado em todos os seus pontos, onde os indivíduos estão inseridos num lugar fixo, em que o menor movimento é controlado, todos os acontecimentos registrados, um lugar onde o poder é exercido sem divisão, segundo uma figura hierárquica contínua, onde o indivíduo é constantemente localizado, examinado e distribuído, constituindo um modelo compacto do dispositivo disciplinar.

O Panóptico funciona como uma espécie de laboratório de poder. Graças a seus mecanismos de observação, ganha em eficácia e em capacidade de penetração no comportamento dos homens; um aumento de saber vem se implantar em todas as frentes do poder, descobrindo objetos que devem ser conhecidos em todas as superfícies onde este se exerça. (FOUCAULT, p. $228,1987)$

Essas tecnologias de poder são denominadas por Foucault (1987) como tecnologias de biopoder, que foram: "rigorosamente aplicadas nas diversas instituições de confinamento que compunham o tecido social sob os cuidados de cada Estado-nação: escola, fábricas, casernas, hospitais, prisões, inclusive casas de família." (SIBILIA, 2015). Essas formas de poder e de controle que são observadas no conto estão simbolicamente expressas no mundo em que vivemos.

Em O conto da Aia, aqueles que fogem à ordem ou não a servem mais, são descartados, ou vão parar no muro, ou vão para as "Colônias" realizar trabalho forçado até a morte. A diferentes tipos de colônias, as piores, em que "há os depósitos de lixo tóxico e a radiação que vaza. Nessas, eles calculam que você tenha três anos de vida no máximo, antes que sua pele se desgrude e saia como luvas de borracha." (O Conto da Aia, p. 295, 2017) e as não tão ruins, onde há agricultura, destinadas às mulheres idosas. 
No neoliberalismo, quando as pessoas já não tem mais nada a perder, sejam recursos ou força de trabalho, elas se tornam simplesmente descartáveis (CRARY, 2016). O autor traz que no entanto, o atual aumento de casos de escravidão sexual e o crescimento do mercado de tráfico de órgãos e partes do corpo, sugerem que os limites da disponibilidade podem ser dilatados, com lucro, para corresponder a novos setores do mercado. Em o Conto da Aia, existe um lugar chamado "A casa de Jezebel", uma espécie de clube, destinado às mulheres que já "não servem" ao sistema, que funciona como um bordel a fim de suprir os desejos dos comandantes. No clube, os desejos sexuais mais secretos dos comandantes são supridos. "Alguns deles fazem isso, têm prazer nisso. É como trepar no altar ou coisa parecida: a sua turma deve ser de receptáculos tão castos. Eles gostam de ver você toda pintada. É só mais uma demonstração de poder nojenta." (ATWOOD, p. 289, 2017).

Isso fala do aniquilamento do sujeito, as mulheres deixam de ser seres humanos e passam a ser tratadas como objeto, não podendo possuir desejo, medo, raiva, alegria ou amor, se tornam indiferentes a vida que são obrigadas a levar. Observemos o diálogo entre a personagem principal e uma antiga colega que ela encontra no clube.

"De modo que aqui estou. Eles nos dão até creme facial. Você deveria arranjar alguma maneira de entrar para cá. Teria três ou quatro bons anos antes que a boceta ficasse gasta e eles mandassem você para o cemitério. A comida não é má e tem bebida e drogas, se você quiser, e só trabalhamos à noite.

- Moira - digo, - Você não está falando sério. - Ela agora está me assustando, porque o que ouço em sua voz é indiferença, uma falta de volição. Então, será que realmente fizeram isso com ela, tiraram-lhe alguma coisa, o quê?, que costumava ser uma parte tão essencial dela? Mas como posso esperar que Moira continue, com minha idealização de sua coragem, que viva à altura dela, que aja de acordo com ela, quando eu mesmo não o faço?" (ATWOOD, p. 296, 2017)

O interessante aqui, é que nesse momento, Offred, a partir de sua conversa com Moira é tensionada e mobilizada a perceber que ela própria perdera sua identidade, sua forma de agir no mundo. O que possibilitou a produção de novos sentidos subjetivos do que se é viver nesta nova realidade, resgatando parte do seu eu do passado e produzindo novas formas de lidar com sua realidade atual.

\footnotetext{
"Sou uma refugiada do passado e, como outros refugiados, repasso os costumes e hábitos de vida que deixei ou fui obrigada a deixar para trás, e tudo aquilo parece igualmente antigo e curioso, visto daqui, e sou igualmente obsessiva a respeito disso. Como um exilado russo tomando chá em Paris, aprisionada no século XX, divago e retorno ao passado, tentando recuperar aqueles caminhos distantes; torno-me sentimental demais, me perco. Pranteio. Isso é prantear, não chorar. Sento-me nesta cadeira e gotejo como uma esponja." (ATWOOD, p. 270, 2017)
} 
Neste momento podemos pensar onde estava o resto do mundo? Com tanta barbárie acontecendo, milhares de assassinatos, tortura, trabalho escravo, porque ninguém tenta impedir a continuidade deste novo mundo? Porque os dividendos de tanta disciplina são claros, a ordem, a segurança e a previsibilidade. Cada um conhece precisamente seu lugar na sociedade, seus direitos e seus deveres, e embora o racionamentos seja severo a comida é para todos, não a criminalidade e as ruas são limpas. Com tanto controle, o Estado tem capacidade de realizar obras públicas e canalizar todos os esforços da nação em prol da recuperação econômica, Giliade passa a ser então alvo do assombro e admiração do mundo por terem conseguido produzir bebês, eles estão garantindo a continuidade da humanidade, eles são a salvação. Alguns países como Canadá se mostram contra tais atitudes, e estão abertos a receber refugiados e apoiam grupos de resistência.

No neoliberalismo o foco do trabalho é o mercado, se os índices econômicos e de desenvolvimento vão bem, há pouca importância para as questões sociais e de direitos humanos básicos. No mundo contemporâneo, pressões conservadoras, uma onda de direita, ou extrema direita se espraia pelo mundo contemporâneo. Líderes de nações como Bolsonaro (Brasil), Donald Trump (Estados Unidos), Victor Orbán (Hungria), Sebastião Piñera (Chile), são alguns exemplos desse crescente (FAUSTO, 2019). Existe nos discurso dessas figuras algo em comum, a volta a uma sociedade segura, em que as pessoas possam andar na rua sem medo e a melhora nos índices econômicos, muito semelhante ao que se falava em $\mathrm{O}$ Conto da Aia, longe aqui de afirmar que tais governos caminham para a realidade de Offred, mas o livros nos possibilita refletir sobre esses discursos salvadores, de que está tudo errado e que agora vamos melhorar.

Ao final do livro, Atwood nos deixa sem respostas, Offred é levada pelos olhos ou por um grupo da resistência, não se sabe ao certo se eles estão ali para ajudá-la.

\footnotetext{
"A camionete está na entrada para carros, as portas duplas permanecem abertas. Os dois, agora um de cada lado, me seguram pelos cotovelos para me ajudar a entrar. Se isto é o meu fim ou um novo começo não tenho nenhum meio de saber: eu me entreguei às mãos de desconhecidos; porque não há outro jeito.

E assim eu entro, embarco na escuridão ali dentro; ou não na luz." (O Conto da Aia, p. , 2017)
}

Nos deixa assim com nossas fantasias, Offred afinal terá uma nova vida ou continuará sofrendo nesta nova realidade? Na contemporaneidade temos o avanço da tecnologia, inteligência artificial, crise ecológica iminente, ameaça diária de armas 
de destruição em massa, internet, nanotecnologia... teremos nós uma nova vida ou descobriremos como é viver no mundo de Offred?

\section{Considerações Finais}

O presente trabalho buscou mostrar que o uso da literatura como possibilidade de debate de diferente processos subjetivos é algo possível, nos permitindo debater temas como relações de poder, consumo, política, meio ambiente, etc. Segundo Homem (2012), a arte é uma imitação da vida, logo, ao fazer a análise de um livro, se está fazendo também uma análise do mundo em que vivemos.

A análise do livro nos permitiu mesmo em uma sociedade distópica como a criada por Atwood, traçar paralelos com a contemporaneidade, não pensando na ficção como algo que deturpa a realidade, mas como ela nos permite pensar a respeito da sociedade em que vivemos, buscando aprender com a arte e criando novas possibilidades frente a vida.

A teoria da subjetividade proposta por González Rey (2017), se mostrou um bom caminho para tal análise, por acreditar que enquanto pesquisador, há a leitura do texto de forma crítica, mas também há mobilização de diferentes processos subjetivos, pois dentro desta perspectiva teórica, o pesquisador é mobilizado por esses processos, que ganham inteligibilidade em uma pesquisa a partir das construções do pesquisador, que irá se alimentar de significados que se vai gradualmente produzindo.

Portanto, o presente trabalho não tinha por objetivo esgotar uma análise, a obra aqui escolhida é de uma grande complexidade, possibilitando debater questões complexas, como o papel da mulher e do homem na sociedade, religião, relações de poder, política, violência, consumo, classe, etc. Assim sendo, a análise aqui feita é um recorte, convido portanto, outros autores a pesquisarem sobre o tema, trazendo novas visões, interpretações e debates. 


\section{Referências}

ARENDT, Hannah. Origens do totalitarismo: antissemitismo, imperialismo, totalitarismo. São Paulo: Companhia de Bolso, 2012.

ATWOOD, Margaret. O Conto da Aia. Rio de Janeiro: Rocco, 2017.

BRAZILIENSE, Correio. Crescem $34 \%$ processos de feminicídio e de violência doméstica, revela CNJ. Disponível em:

$<$ https://www.correiobraziliense.com.br/app/noticia/brasil/2019/03/11/internabrasil,742285/crescem-34-processos-de-feminicidio-e-de-violencia-domesticarevela.shtml>. Acesso em: 27 abr. 2019.

CRARY, Jonathan. 24/7: capitalismo tardio e os fins do sono. São Paulo: Ubu, 2016. ÉPOCA. Ministério do Meio Ambiente quase zera verba de combate à mudança climática. Disponívelem:

<https://epocanegocios.globo.com/Brasil/noticia/2019/05/epoca-negocios-ministeriodo-meio-ambiente-quase-zera-verba-de-combate-a-mudanca-climatica.html>.

FOLHA DE S.PAULO. (2019). Vítimas de casamentos forçados rompem silêncio no Camboja depois de 40 anos. Disponível:

https://www1.folha.uol.com.br/mundo/2019/01/vitimas-de-casamentos-forcadosrompem-silencio-no-camboja-depois-de-40-anos.shtml [Accessed 29 Jan. 2019].

FOUCAULT, Michel. Vigiar e punir: nascimento da prisão. Petrópolis: Editora Vozes, 1987.

GONZÁLEZ REY, Fernando Luis; MARTÍNEZ, Albertina Mitjáns. Subjetividade: teoria, epistemologia e método. Campinas: Alínea, 2017.

GROSS, Fredéréric. Desobedecer. São Paulo: Ubu Editora, 2018.

HARARI, Yuval Noah. 21 lições para o século 21. São Paulo: Companhia das Letras, 2018.

HOBBES, Thomas. Leviatã: ou Matéria, Forma e Poder de um Estado Eclesiástico e Civil. São Paulo: Martins Fontes, 2003. 
HOMEM, Maria Lucia. No limiar do silêncio e da letra. São Paulo: Boitempo Editorial, 2012.

IBGE. Mulher estuda mais, trabalha mais e ganha menos do que o homem. Disponível em: <https://agenciadenoticias.ibge.gov.br/agencia-noticias/2012agencia-de-noticias/noticias/20234-mulher-estuda-mais-trabalha-mais-e-ganhamenos-do-que-o-homem>. Acesso em: 27 abr. 2019.

LACAN, Jacques. O Seminário, livro 3: psicoses. Rio de Janeiro: Zahar, 2009.

LEITE, Dante Moreira. Psicologia e literatura. 5. ed. São Paulo: Unesp, 2003.

MAMILOS. Mudanças Climáticas Na Sua Vida. Disponível em:

<https://www.b9.com.br/108233/mamilos-197-mudancas-climaticas-na-sua-vida/>. Acesso em: 21 maio 2019.

MORGANTE, Mirela Marin; NADER, Maria Beatriz. O patriarcado nos estudos feministas: um debate teórico. Anais do. XVI Encontro Regional de História da ANPUH-Rio, 2014.

NEXO. Quais os fatos reais que inspiraram the handmaid's tale. 2017.

Disponível em: <https://www.nexojornal.com.br/expresso/2017/11/28/Quais-os-fatosreais-que-inspiraram-The-Handmaid's-

Tale?utm_campaign=Echobox\&utm_medium=Social\&utm_source=Twitter\#Echobox= 1550250440>. Acesso em: 13 fev. 2017.

PARUCKER, Isabela Gomes. "Vivíamos nas Lacunas entre as Histórias": Ficção, História e Experiência Feminina em The Handmaid's Tale, de Margaret Atwood.

Dissertação (Mestrado) - Curso de História, Universidade de Brasília, Brasília, 2018.

ROCHA, Eduardo. DIREITO, TEORIA DA SUBJETIVIDADE E POLÍLITCAS PÚBLICAS: intersessões possíveis e o desnudamento de verdades jurídicas estereotipadas. In: CAMPOLINA, Luciana de O.; MORI, Valéria D.. Diálogos com a teoria da subjetividade: reflexões e pesquisas. Curitiba: Crv, 2017. p. 143-160.

S.PAULO, Folha de. Exército silencia sobre investigação de mortes com 80 tiros por militares no Rio. 2019. Disponível em:

<https://www1.folha.uol.com.br/cotidiano/2019/04/exercito-silencia-sobre- 
investigacao-de-mortes-com-80-tiros-de-militares-no-rio.shtml>. Acesso em: 21 maio 2019.

SANABIO-HECK, Elisa Tavares. O Lenhador: A pedofilia em uma visão analíticocomportamental.... In: DE-FARIAS, Ana Karina Curado Rangel; RIBEIRO, Michela Rodrigues. Skinner vai ao cinema. Brasília: Instituto Walden4, 2014. p. 193-213. SIBILIA, Paula. $\mathrm{O}$ homem pós-orgânico: $\mathrm{A}$ alquimia dos corpos e das almas à luz das tecnologias digitais. Rio de Janeiro: Contraponto, 2015. 